Research Article

\title{
Unconfined and Triaxial Compression Tests on Hollowed Cylindrical Sandstones to Explore the Infilling Effects on the Deformation and Mechanical Behaviors
}

\author{
Yong Liu, ${ }^{1}$ Xiao Li, ${ }^{2}$ Lei Weng $\mathbb{D}^{3},{ }^{3}$ Qiuhong $W u,{ }^{1}$ and Haifan Wang ${ }^{2}$ \\ ${ }^{1}$ Work Safety Key Lab on Prevention and Control of Gas and Roof Disasters for Southern Coal Mines, \\ Hunan Provincial Key Laboratory of Safe Mining Techniques of Coal Mines, Hunan University of Science and Technology, \\ Xiangtan 411201, China \\ ${ }^{2}$ School of Resources, Environment and Safety Engineering, Hunan University of Science and Technology, Xiangtan 411201, China \\ ${ }^{3}$ School of Civil Engineering, Wuhan University, Wuhan 430072, China \\ Correspondence should be addressed to Lei Weng; wenglei08@gmail.com
}

Received 6 August 2021; Accepted 3 September 2021; Published 17 September 2021

Academic Editor: Aniello Riccio

Copyright (c) 2021 Yong Liu et al. This is an open access article distributed under the Creative Commons Attribution License, which permits unrestricted use, distribution, and reproduction in any medium, provided the original work is properly cited.

\begin{abstract}
In practical engineering, the mechanical properties of the surrounding rock often reflect the bearing capacity of the support. To investigate the relations between the surrounding rock and the support, solid specimens, hollowed cylinders, and hollowed cylinders filled with two kinds of cement mortars are tested under unconfined and conventional triaxial compressions. The effects of the infilling on the stress-strain curves, deformation features, mechanical properties, and failure patterns are schematically investigated. The results show that under the triaxial compression condition, each infilled specimen exhibits obvious residual carrying capacity though a slight stress drop occurs after the peak stress. The cement mortar exerts a positive effect on the carrying capacity of the rock, and the infilling having a higher strength and stiffness contributes to a more pronounced enhancement of the overall strength of the specimens. Under the triaxial compression condition, merely a dominated shear fracture can be seen on the surfaces, and with relatively high confining pressure $\left(\sigma_{3}=20\right.$ and $\left.30 \mathrm{MPa}\right)$, both the rock and cement mortar were cut into two parts by the dominated shear fracture. The laboratory tests in this study provide a simple and feasible way of investigating the interaction of the support system with the surrounding rock.
\end{abstract}

\section{Introduction}

The creation of opening in deep underground often induces excavated damage zones (EDZ) around the roadway, resulting from the redistribution of the initial geo-stress field [1-4]. With the increase in the distance to the periphery of the opening, the tangential stress decreases from the maximum magnitude to the original state, while the radial stress increases from zero to the original state. In this regard, the surrounding rock adjacent to the excavation profile is actually in a nonuniform stress distribution state [5-8], making the deformation and failure of the surrounding rock extremely complicated [9-12]. Accordingly, the pseudo triaxial compression tests on the rock specimens may not be able to fully meet the demand of actual engineering [13-16]. Therefore, it is necessary to investigate the deformation behaviors and mechanical properties of the rock specimen under a nonuniform stress state.

Testing on hollowed cylinder specimens is one of the simplest methods for studying the mechanical properties of rock under the nonuniform stress state [17-21]. Hollow cylinder-type specimens have been widely adopted in a variety of investigations [22, 23], such as simplified underground openings [24-26] and stability analysis of the drill hole wall $[27,28]$. The hollowed cylinder tests have two aspects of advantages over the pseudo triaxial compression tests. The first advantage is that the hollowed cylinder tests can conduct physical simulations at a reduced scale of complicated stress conditions and paths of rock mass 
engineering. The second advantage is the simplicity in preparation and testing procedure of hollowed cylinder specimen. In this regard, Yang [29] investigated the influences of confining pressure and the hole diameter on the peak strength, deformation, and crack damage behaviors of hollowed sandstone specimens. Yang [30] evaluated the internal damage behaviors of the hollowed cylindrical sandstone specimens based on the analysis of three-dimensional microstructures. Wang et al. [31] used hollowed cylindrical granite specimens with coupled external and internal confining pressures to investigate the effect of the radial stress gradient to the triaxial strength properties. Zhou et al. [32] developed a new rock mechanical experimental device to conduct compression tests with complex stress path of varying stress magnitudes and orientations. Li et al. [33] discussed the effects of comprehensive stress paths on the mechanical properties of the hollow cylinder specimen. The aforementioned studies provide deep understandings on the deformation characteristics and mechanical properties of rock subjected to different stress conditions and stress paths.

In practical engineering, the mechanical properties of the surrounding rock often reflect the bearing capacity of the support [34-36]. Wang [34] found that there has always been sufficient support intensity on the surface of the surrounding rock, which can be rewarded with a significant reduction of rock deformation. The large support intensity can only cause less reduction of roadway deformation. This indicated that the mechanical properties of the surrounding rock can be significantly affected by the support forces. In addition, the bonding state between the rock and the support also has an important effect in the deformation and failure of the surrounding rock [37]. However, few experimental studies on the relationships between the support and the surrounding rock using the hollowed cylinder tests have been publicly reported [38]. Therefore, it is of great practical and theoretical significance to investigate the effect of the support on the rock deformation and instability by conducting laboratory experiments on the hollowed cylindrical specimens.

The first aim of this study is to investigate the influence of the infillings on the deformation and mechanical performances of hollowed sandstones under unconfined and triaxial compression tests. This study also aims to extend the application of the hollowed cylinder tests to explore the relationship between the surrounding rock and support for deep underground engineering. To this end, hollowed cylinders filled with two kinds of cement mortar having different strengths are subjected to unconfined and conventional triaxial compression tests. The solid specimens and hollowed specimens are also prepared and tested under the same stress conditions for comparison purpose. The effects of the infilling on the stress-strain curves, deformation features, mechanical properties, and failure patterns are investigated in-depth. The experimental results can provide a meaningful reference to understand the relations between the surrounding rock and the support in practice.

\section{Experimental Methodology and Preparation}

2.1. Specimen Preparation. The sandstone specimens for experimentation were taken from a sandstone quarry located in Changsha, Hunan province of China. The sandstone has the characteristics of grey color, medium grain, and good homogeneity. The solid cylindrical specimens with a diameter of $50 \mathrm{~mm}$ and a height of $100 \mathrm{~mm}$ were first cored from an intact sandstone block. Then, the solid specimens were processed into hollowed cylinders with an inner diameter of $16 \mathrm{~mm}$. Finally, cement mortars were prepared and used to fill in the inner hole, as shown in Figure 1. In this study, two kinds of cement mortar having different mixture ratios were taken into account.

The mixed proportions were 1.0:5.27:1.16 (cement: sand: water) for the low-strength cement mortar and 1.0 : $3.47: 0.64$ (cement: sand: water) for the high-strength cement mortar. The infilled specimens were cured in controlled conditions at a temperature of $25^{\circ} \mathrm{C}$ and a relative humidity of $95 \%$ for 28 days following the American Society of Civil Engineering (ASCE) standard [39]. In doing this, the cement mortar can serve at its best performance and generate good adhesions between the cement mortar and the prefabricated hole. It should be noted that the two ends of the infillings were approximately $2.5 \mathrm{~mm}$ lower than the loading surface of the rock (see Figure 1). Such a configuration ensures that the cement mortar does not have direct contact with the platen during the loading period. Therefore, the cement mortar was exempt from the direct force by the platen, which is beneficial for investigating the interaction of the cement mortar with the rock structure.

The basic mechanical performances of the cement mortars and the sandstone were obtained by conducting unconfined compression tests and Brazilian disc tests, as listed in Table 1. It can be seen that due to the different mixture ratios, the high-strength cement mortar (HSCM) exhibits much higher strength and stiffness than that of the low-strength cement mortar (LSCM). The sandstone specimen has distinct mechanical parameters compared to the cement mortar, for example, the unconfined compressive strength (UCS) of the sandstone is 2.6 times that of the HSCM and 6.2 times that of the LSCM, and the tensile strength of the sandstone is 0.9 times that of the HSCM and 3.1 times that of the LSCM. In this regard, four groups of specimens with different configurations were derived for the subsequent experimentation, such as the solid cylindrical specimen (SC), hollowed cylindrical specimen (HC), hollowed cylindrical specimen infilled with HSCM (HCHSCM), and hollowed cylindrical specimen infilled with LSCM (HC-LSCM).

2.2. Testing Methods. Monotonic unconfined compression tests and triaxial compression tests were conducted on the specimens using a hydraulic servo-controlled RMT-150C loading system, as presented in Figure 2. The axial stress value was obtained by the reading of loading cell, and the axial strain was the overall strain of the sample measured by a linear variable differential transformer (LVDT), which 


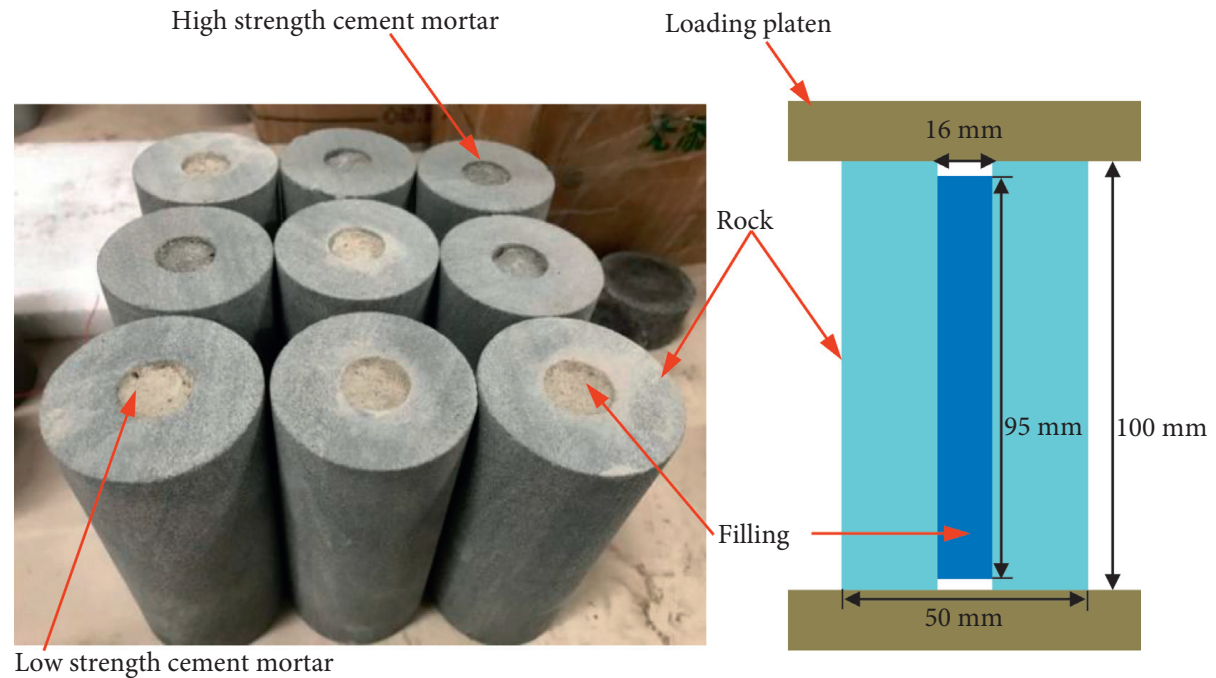

FIGURE 1: Configuration of the infilled specimens.

TABLe 1: Physical and mechanical properties of the cement mortars and the sandstone.

\begin{tabular}{lccc}
\hline Properties & LSCM & HSCM & Sandstone \\
\hline Density $\left(\mathrm{g} / \mathrm{cm}^{3}\right)$ & 2.01 & 2.10 & 2.32 \\
P-wave velocity $(\mathrm{m} / \mathrm{s})$ & 1906 & 2240 & 2756 \\
Poisson's ratio & 0.22 & 0.25 & 0.27 \\
Young's modulus $(\mathrm{GPa})$ & 5.2 & 10.0 & 14.3 \\
UCS $(\mathrm{MPa})$ & 13.2 & 31.6 & 82.2 \\
Tensile strength $(\mathrm{MPa})$ & 1.31 & 4.83 & 4.11 \\
\hline
\end{tabular}

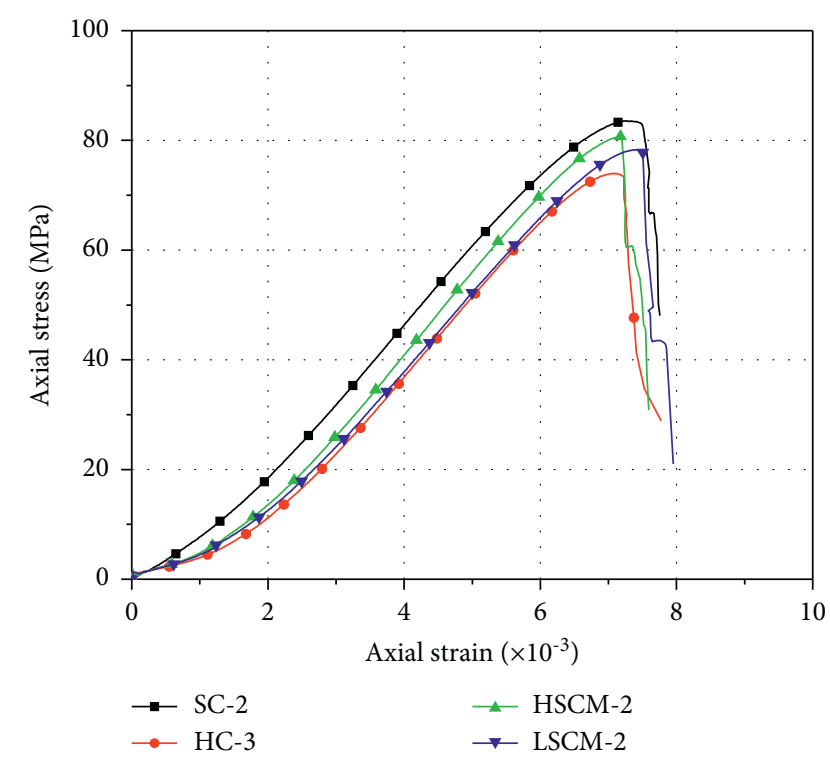

FIGURE 2: Stress-strain curves of the specimens under unconfined compression.

records the movement of the loading piston. The axial loading speed was set to $0.002 \mathrm{~mm} / \mathrm{s}$ using a displacement control module. Four levels of confining pressure, including $5 \mathrm{MPa}, 10 \mathrm{MPa}, 20 \mathrm{MPa}$, and $30 \mathrm{MPa}$, were set in the triaxial compression tests, and the loading rate of the confining was set to $0.1 \mathrm{MPa} / \mathrm{s}$ using a pressure control module. Under such loading speeds, the strain rate of the specimen is sufficiently low so as to be a quasi-state loading condition.

\section{Experimental Results and Analyses}

3.1. Stress-Strain Curves. Figures 2 and 3 present the stressstrain curves of the specimens under unconfined compression and triaxial compression conditions. It is seen that all groups of the specimens experience four stages of initial compaction, linear elasticity, yielding, and postfailure. However, different types of the infillings and different confining pressures have distinct contributions to the four stages shown in the stress-strain curve. Under high confining pressures, it is shown that the solid specimen has a large deformation in the initial stage, as shown in Figure 3(a). It is contributing to the natural microfissures in the specimen. In terms of the postpeak stage, upon unconfined compression, all the specimens exhibit a remarkable stress drop at failure, indicating a typical brittle failure mode. Such a phenomenon can also be observed in the hollowed specimens with confining pressure, as shown in Figure 3(b). This is because the existing hole induces sever local stress concentration around the inner hole surface due to the axial force and external confining pressure and provides sufficient room for rock deformation so as to result in brittle manner at the onset of failure. However, this is not the case for the infilled specimens with confining pressure. As presented in Figure 3(c) and 3(d), due to the existence of the cement mortar in the inner hole, the specimen still performs a residual carrying capacity (or residual strength) though a slight stress drop occurs. Furthermore, the residual strength increases with the increase in the confining pressure. This phenomenon indicates that the infilling material has a significant effect on the postfailure mechanical behaviors. In the case of this study, the residual carrying capacity of the infilled specimens is mainly rested on the interfacial friction between the rock and the infilling, as well as the support effect of the infillings. It is seen that under the 


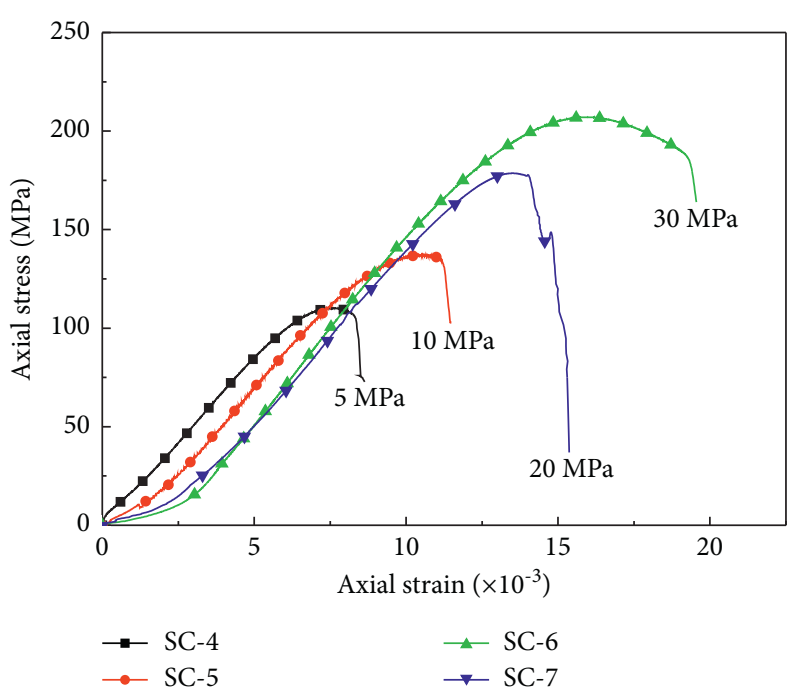

(a)

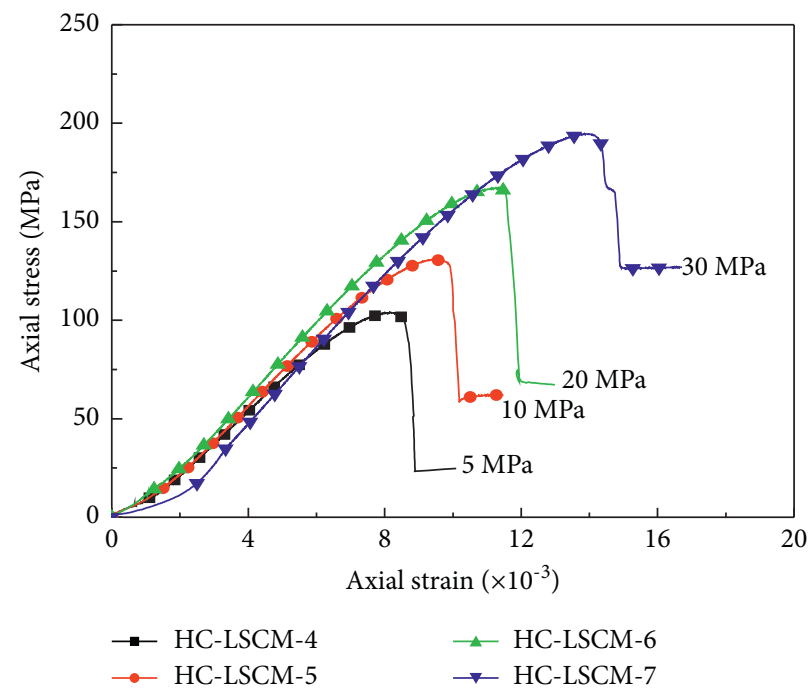

(c)

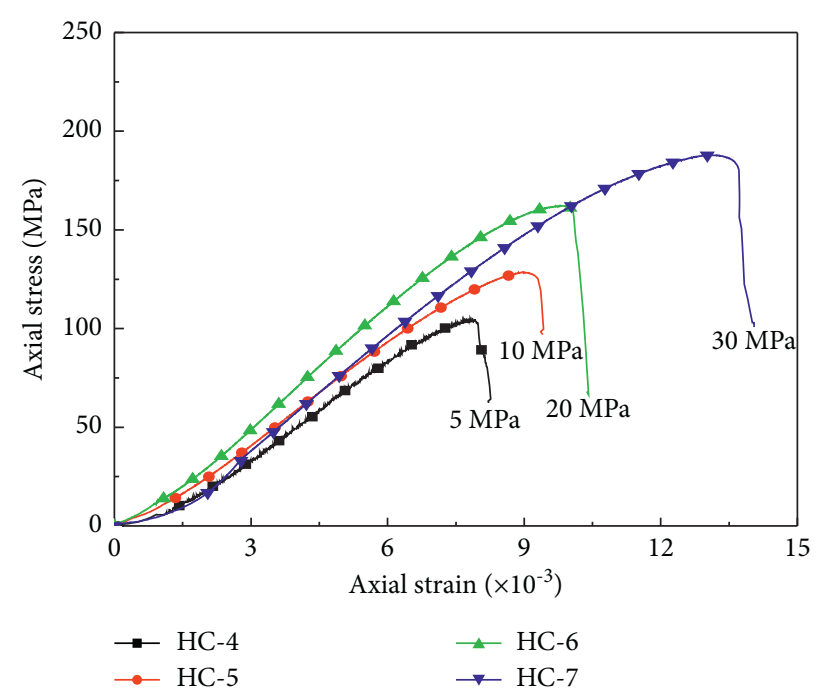

(b)

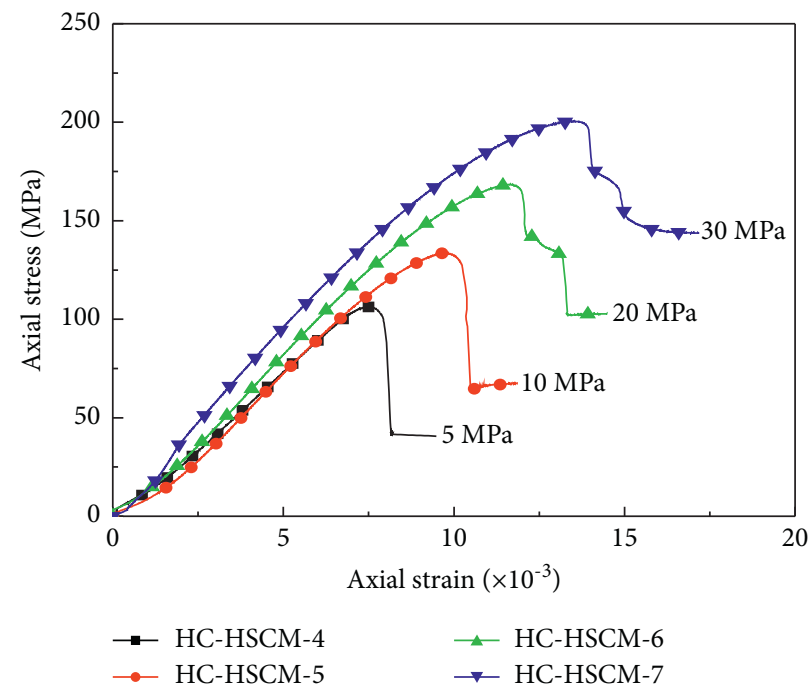

(d)

Figure 3: Stress-strain curves of the specimens under triaxial compression: (a) SC specimens, (b) HC specimens, (c) HC-LSCM specimens, and (d) HC-HSCM specimens.

identical confining pressure, the residual strengths of the HC-HSCM specimens are greater than those of the HCLSCM specimens, indicating that the high-strength cement mortar is more advantageous to enhance the strength of the hollowed specimens.

\subsection{Deformation and Mechanical Properties. As mentioned} in Section 3.1, for different test scenarios, the stress-strain relations at the prepeak stage exhibit distinct features as a result of the infilling and confining pressure. To study the prepeak deformation properties during the test process, the crack closure strain $\left(\varepsilon_{\mathrm{cl}}\right)$, plastic strain $\left(\varepsilon_{p}\right)$, and elastic strain $\left(\varepsilon_{e}\right)$ under different stress levels and inclusions were investigated. The crack closure strain was defined as the strain as a result of the crack closure or sliding during the initial compaction stage but not belonging to the linear elastic strain [40-42]. In this regard, the crack closure strain $\left(\varepsilon_{\mathrm{cl}}\right)$ can be obtained by the reading of the intersection of the strain axis with the elastic slope (marked as line $\mathrm{AB}$ ) as illustrated in Figure 4 . The elastic strain $\left(\varepsilon_{e}\right)$ was obtained as the horizontally projected length of the elastic slope (marked as line CD) through the peak value stress. The plastic strain $\left(\varepsilon_{p}\right)$ was the residual of the peak strain subtracting the crack closure strain and elastic strain [42]. A typical stress-strain curve illustrating the determination of the aforementioned strains is presented in Figure 4.

The relationships between the crack closure strain, plastic strain, and elastic strain and the confining pressure and the sample configuration are plotted in Figure 5. Both the elastic and plastic strains increase with ascending the confining pressure, which is a general tendency for all the test scenarios. This change tendency of elastic strain is more significant for the solid specimens than the other three 


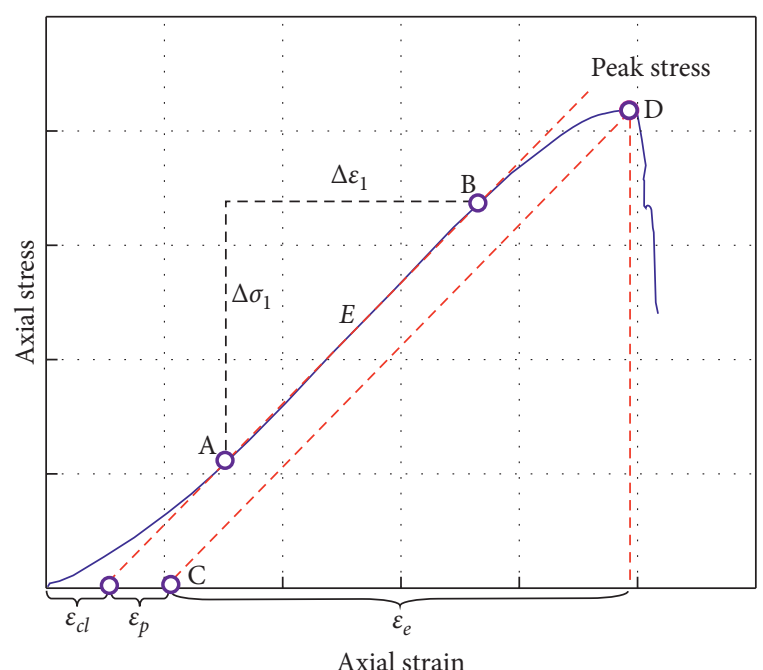

Figure 4: A typical stress-strain curve illustrating the crack. Closure strain $\left(\varepsilon_{\mathrm{cl}}\right)$, elastic strain $\left(\varepsilon_{e}\right)$, and plastic strain $\left(\varepsilon_{p}\right)$.

groups. For example, under the same confining pressure, the magnitude of the elastic strain for the solid specimen is greater than those for the hollowed specimen, HC-LSCM specimen, and HC-HSCM specimen. As for the crack closure strain, it is seen that when the confining pressure changes from $5 \mathrm{MPa}$ to $30 \mathrm{MPa}$, the crack closure strains show monotonic increase trends for all the four test scenarios. Similarly, the increase tendency of the crack closure strain is significant only for the solid specimens but statistically insignificant for the other three groups.

In addition, it can be seen from Figures 5(a) to 5(d) that, for each type of the specimen configuration, the crack closure strain derived from the unconfined compression test is greater than that obtained from the triaxial compression with relative low confining pressures. This phenomenon occurs because the crack closure strain discussed here is the vertical strain caused by the axial force and the confining pressure if applicable. The confining pressure, however, has a negative influence on the increase in the crack closure strain due to Poisson's effect. Therefore, with the existence of the confining pressure (in particular with low confining pressure), the crack closure strain of the specimen in the triaxial compression tests is smaller than that detected under unconfined compression condition.

Figure 6 shows the variations in the elastic modulus of the specimens with different confining pressures. A general trend as observed from Figure 6 is that a greater confining pressure leads to a much higher elastic modulus. It is noted that the elastic modulus of the solid specimens at the confining pressure of $10 \mathrm{MPa}$ is obviously lower than that of the other groups. The most possible reason is the rock heterogeneity. This trend is the case for all the groups of the specimens including the hollowed specimens. Considering the infilling effects on the elastic modulus, it is seen that under the same confining pressure, the elastic modulus has no conclusive change trend due to the infillings. This may be attributed to the complex mechanical interaction between the rock and infilling material.
Figure 7 presents the strengths of all the groups of specimens under different confining pressures. Similar to the elastic modulus, the strength of the specimen increases with increasing confining pressure, irrespective of the existence of the infilling. However, the infilling has significant influences on the strength enhancement of the specimens. The solid specimens exhibit the highest strengths compared to the hollowed specimens, LSCM-filled specimens, and HSCMfilled specimens. This is because, on one hand, the strength and elastic modulus of the sandstone are both higher than those of the cement mortar (see Table 1). On the other hand, the solid specimen has a better structure integrity as compared to the infilled specimen.

The strengths of the HC-HSCM specimens are slightly greater than those of the HC-LSCM specimens, and both of the HC-HSCM and HC-LSCM specimens perform greater strengths than the hollowed specimens. This phenomenon indicates that the cement mortar exerts a positive effect on the carrying capacity of the rock, and the infilling having a higher strength and stiffness contributes to a more pronounced enhancement of the strength.

3.3. Failure Patterns. Under unconfined compression condition, the four groups of specimens fail mainly in shear manners with a few local tensile fractures, as shown in Figure 8. For the HC specimens, the rock at the periphery of the hole does not show obvious failure characteristics. The infilled specimens present both shear and tensile failures. However, some rock does not spall and still stuck with the cement mortar, as shown in Figure $8(\mathrm{c})$ and $8(\mathrm{~d})$. It is showing that the filling material has a certain effect on the failure modes.

Figure 9 shows the failure modes of the specimens under the triaxial compression conditions. A dominated shear fracture can be seen on the surfaces for all the specimens after the triaxial compression tests. For the solid specimens, local tensile failure also occurs at low confining pressures (for example, $\sigma_{3}=5$ and $10 \mathrm{MPa}$ ), as shown in Figure 9(a). Upon close inspections on the hollowed specimens, it is found that obvious splitting failures occur around the inner hole wall when the confining pressure reaches as high as $20 \mathrm{MPa}$ and $30 \mathrm{MPa}$ in Figure 9(b). Such a phenomenon is similar to previous studies owing to the complex nonuniform stress state $[24,25,36,43]$. In this regard, the minimum principal stress at the periphery of the hole is the lowest, resulting in progressive failure at the periphery of the hole under the combined high confining pressure and axial loading. However, the hollowed specimens show a typical shear-dominated fashion on the outer surface.

For the infilled specimens, merely one shear failure surface can be observed on the specimens at the confining pressure of $5 \mathrm{MPa}$ and $10 \mathrm{MPa}$ in Figures 9(a) and 9(d). The rock fragments are tightly stuck with the cement mortar, and the cement mortars have no clear fracture surface. However, under relatively high confining pressure (for example, $\sigma_{3}=20 \mathrm{MPa}$ and $30 \mathrm{MPa}$ ), the final shear fracture cuts across the rock and the cement mortar into two parts. The results indicate that the carrying capacity of the specimens is 


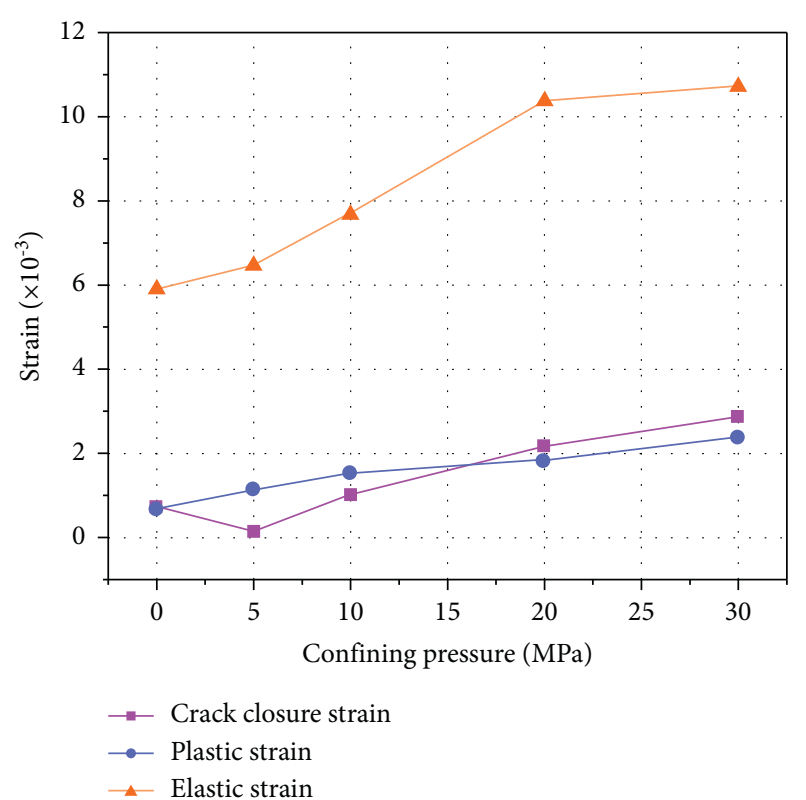

(a)

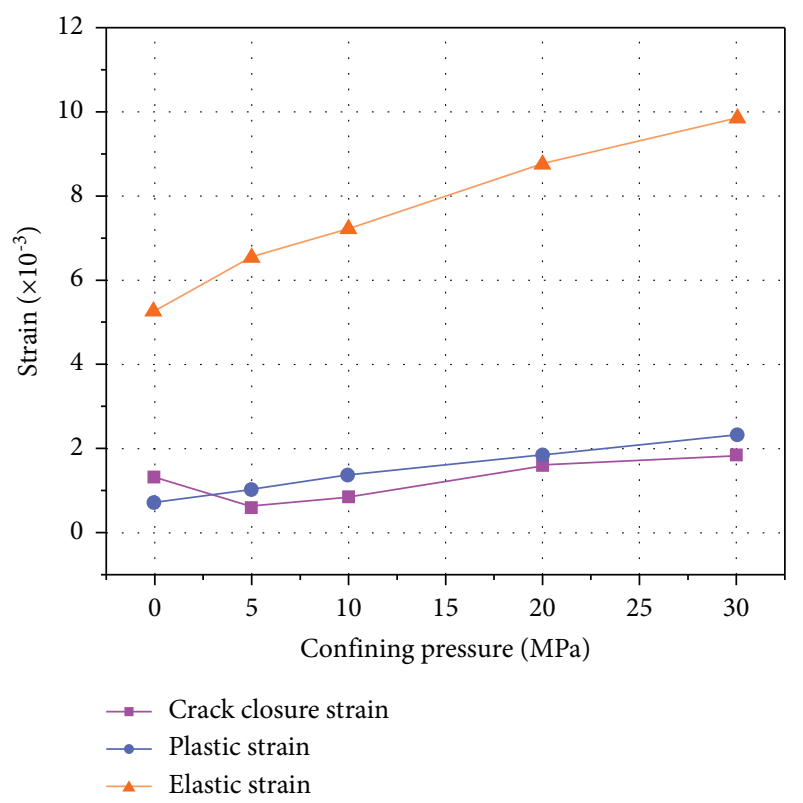

(c)

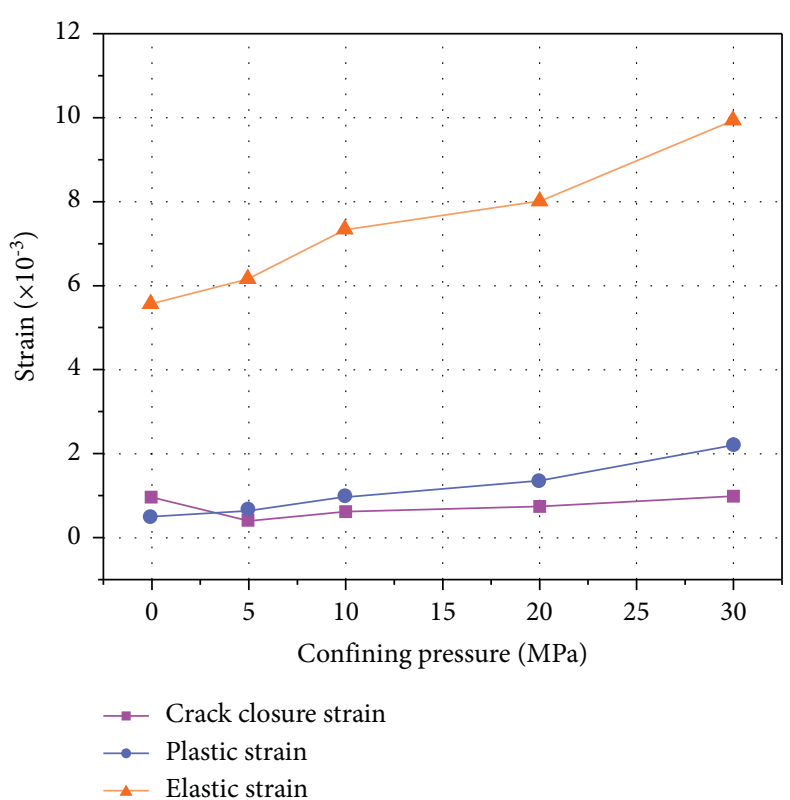

(b)

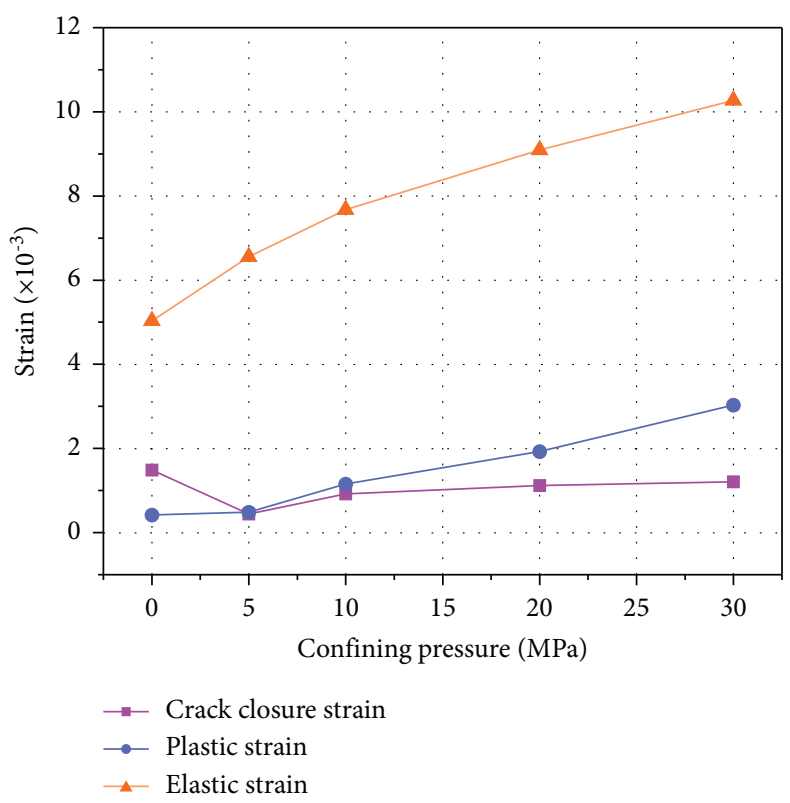

(d)

FIGURE 5: Variations in the crack closure strain, plastic strain, and elastic strain for the four groups of specimens under varying confining pressures: (a) solid specimen, (b) hollowed specimen, (c) HC-LSCM specimen, and (d) HC-HSCM specimen.

significantly reinforced by the infilling material [44], which provides not only a radial constraint at the inner hole but also an axial friction force to the rock structure.

\section{Discussion}

In this study, the infilling effects on the mechanical and deformation behaviors of the cement mortar-infilled specimens were experimentally investigated under the unconfined and triaxial compression conditions. The height of the infilling surface was set as $2.5 \mathrm{~mm}$ lower than the rock surface, so that the infilling material was not directly loaded by the axial force during the test. In doing this, the infilling material exerts a similar support function as illustrated in Figure 10. The hollowed cylindrical rock serves as a simplified underground opening and the surroundings, while the infilling is used to mimic the support system. Under the combined conditions of axial loading and lateral confining pressure, a radial force between the rock and the infilling will be induced in response to the radial deformations of the infillings and the rock. The magnitude of the radial force is heavily related to the confining pressure, axial stress, and elastic moduli of the infilling and the rock. Therefore, the radial force generated by the infilling is not a constant value 


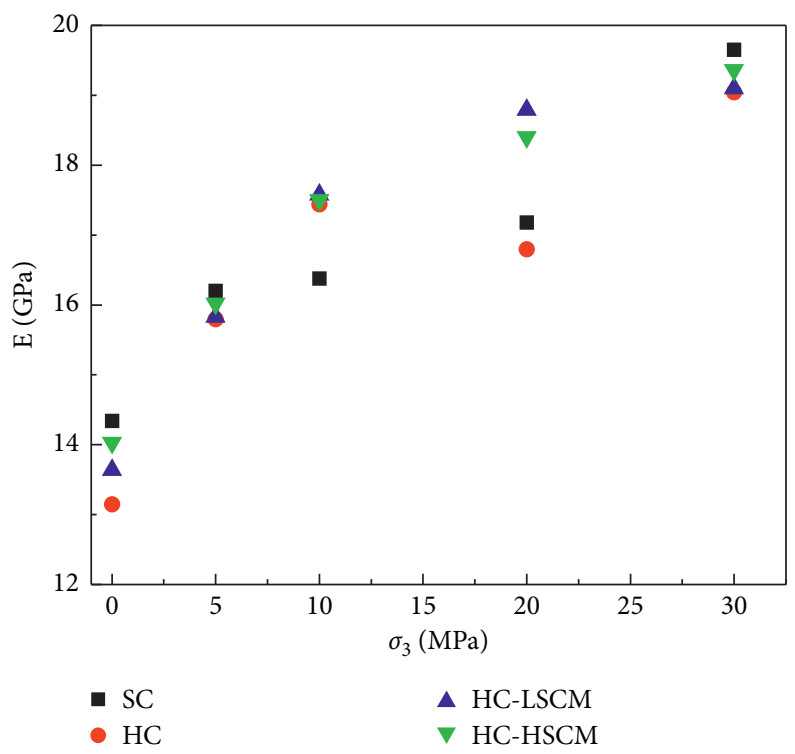

FIgURE 6: Changes in elastic modulus against the confining pressure.

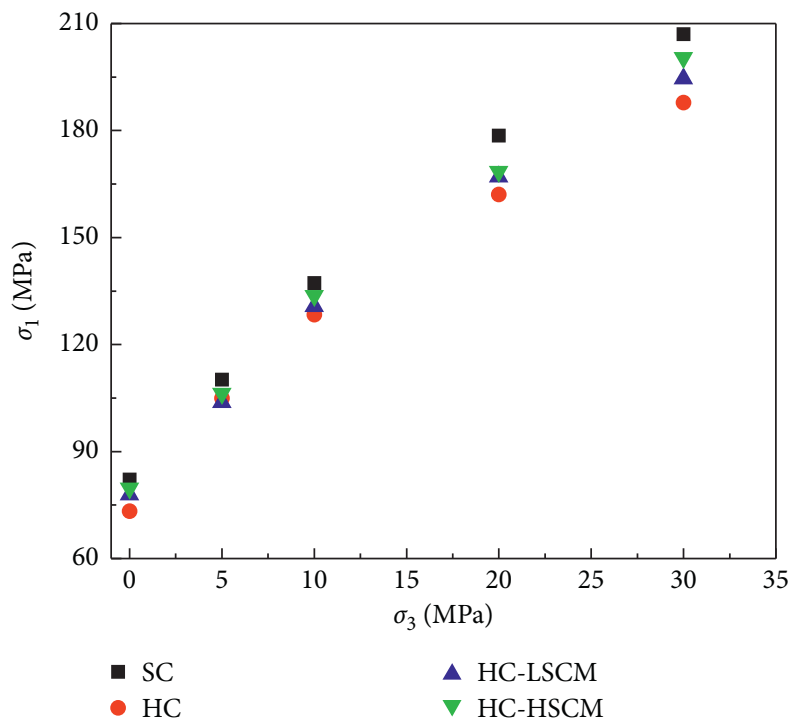

FIGURE 7: Relation between confining pressure and strength.

during the loading compression process, which gradually increases along with the axial stress, reflecting a mutual mechanical responses between the infilling and the rock. This is much different from the previous study [31], in which a constant inner pressure was applied in the inner hole during the loading process. The specimen configuration by Wang et al. [31] is similar to the conventional support concept that the support system with sufficient high strength and stiffness is adopted. However, the surrounding rock and the support are essentially separated without taking the mutual actions into account. In this paper, the interactions of the support (infilling) and the rock have been adequately considered. At the initial loading stage, the infilling shows limited support effect due to the small deformation of the rock. With continuing loading, the deformation of the rock increases gradually and hence the rock squeezes the support structure. In this regard, the support structure exerts a back forward compression to the rock, playing a positive support role to resist the subsequent deformation of the rock. At this stage, the support has significant impacts on the reinforcement of the carrying capacity, similar to the fundamentals of the New Austrian Tunnelling Method (NATM) [45]. The core of the NATM is the consideration of the surrounding rock as parts of the entire support system and permits the surrounding rock having a certain deformation to fully utilize the self-bearing capacity of the surrounding rock. The laboratory experiments in this study can well illustrate the NATM concept and provides an effective way of investigating the interaction of the support system with the surrounding rock. 


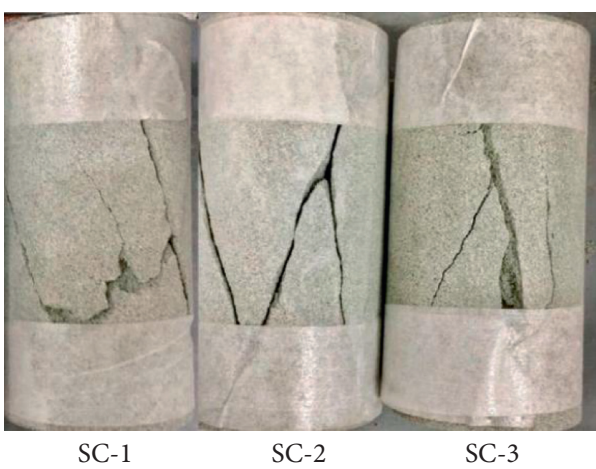

(a)

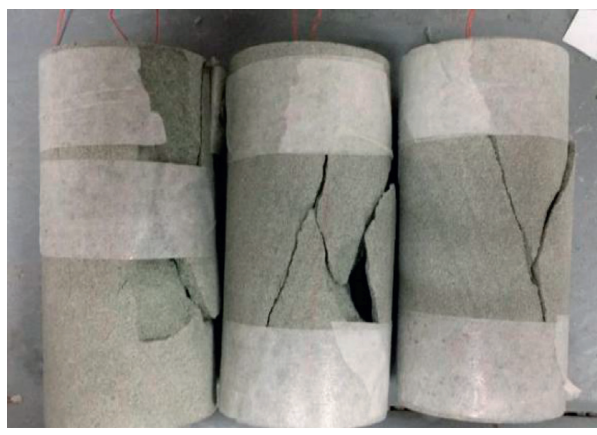

HC-LSCM-1
HC-LSCM-2

(c)

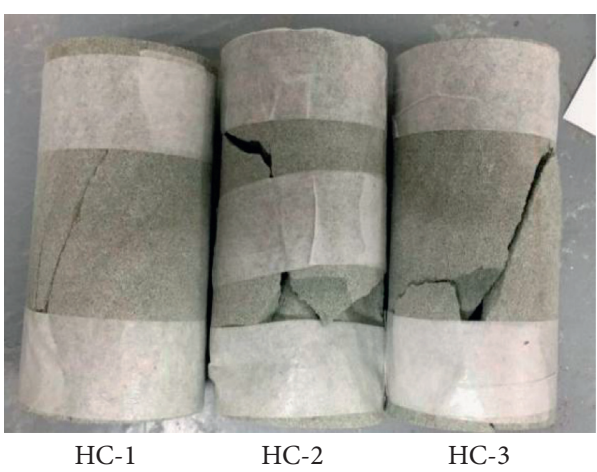

(b)

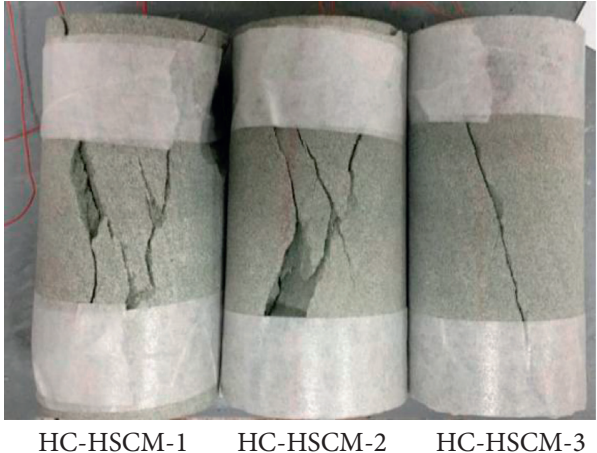

(d)

FIGURE 8: Failure modes of specimens under uniaxial compression: (a) SC specimens, (b) HC specimens, (c) HC-LSCM specimens, and (d) HC-HSCM specimens.

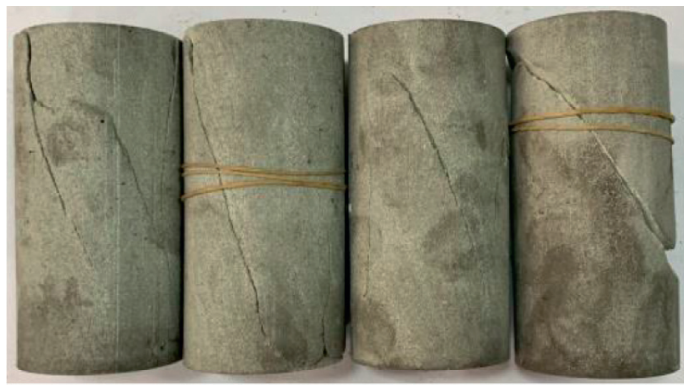

$\sigma_{3}=5 \mathrm{MPa}$
10
30
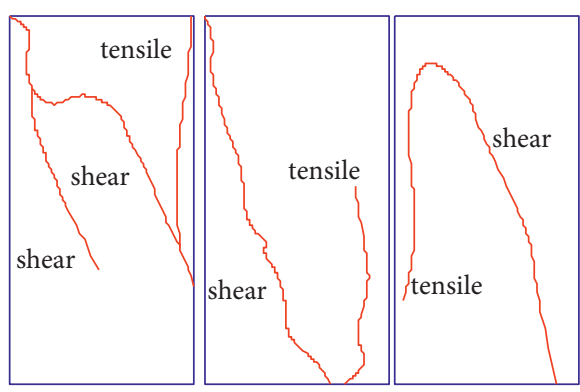

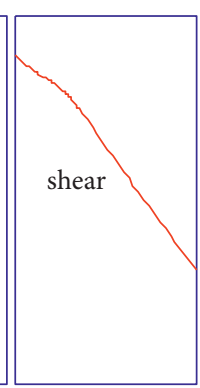

(a)

Figure 9: Continued. 

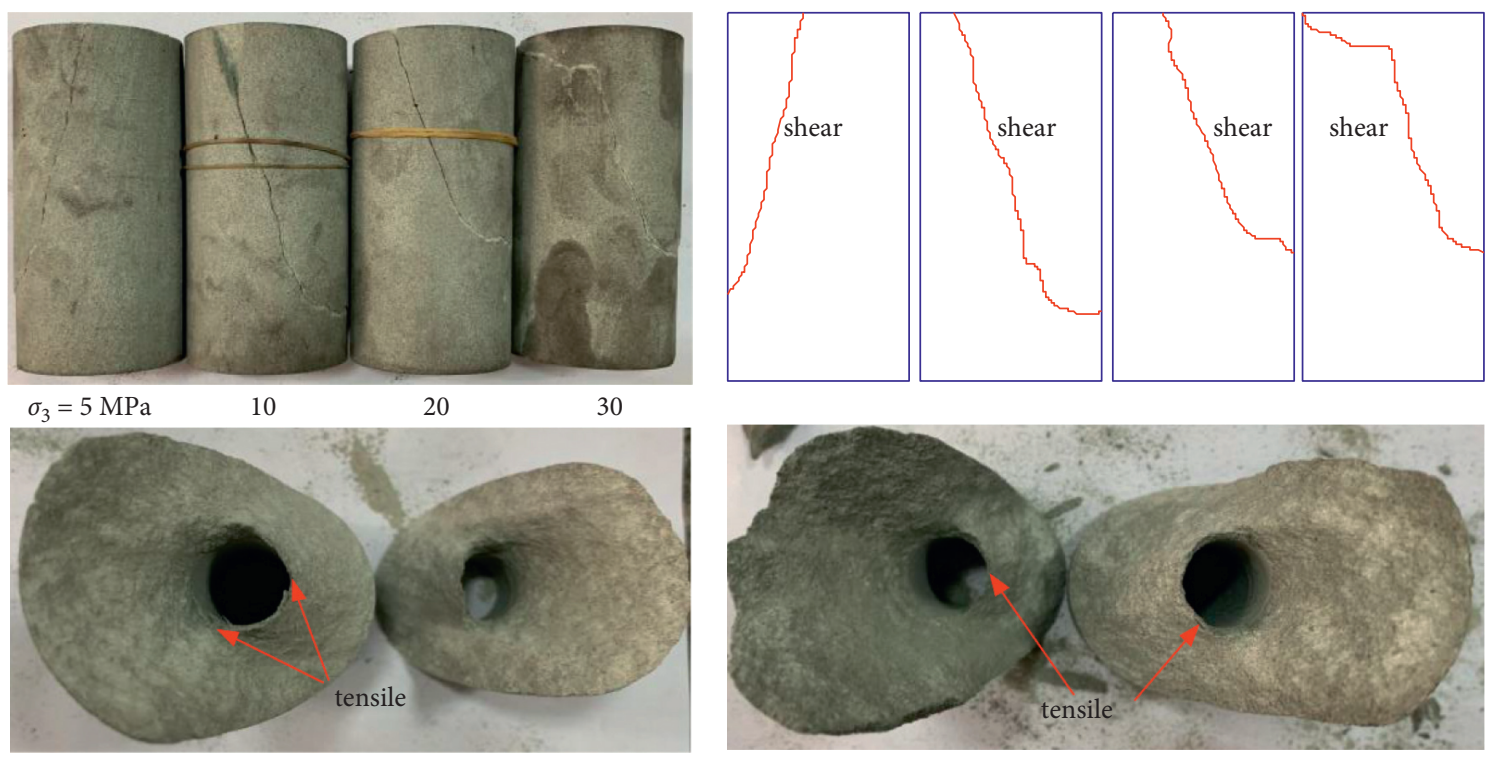

$\sigma_{3}=20 \mathrm{MPa}$

$\sigma_{3}=30 \mathrm{MPa}$

(b)
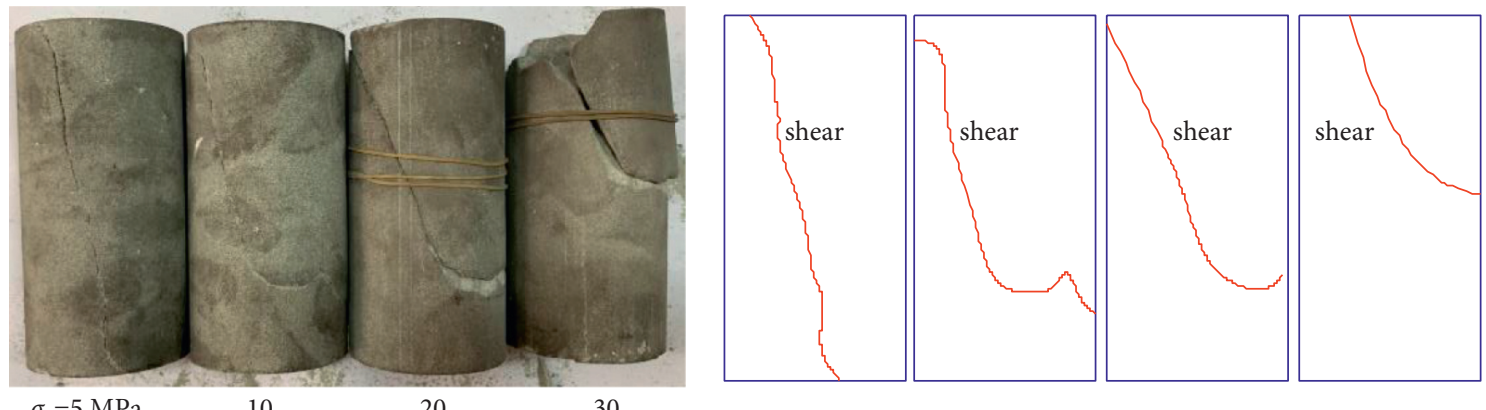

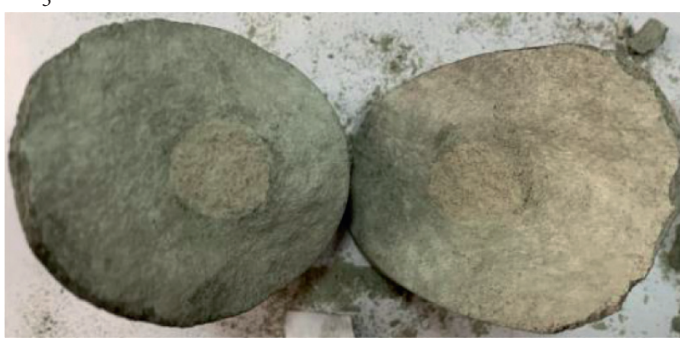

$\sigma_{3}=20 \mathrm{MPa}$

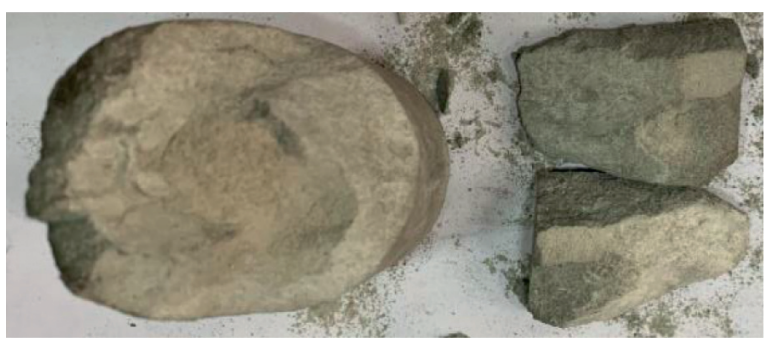

$\sigma_{3}=30 \mathrm{MPa}$

(c)

FIGURE 9: Continued. 

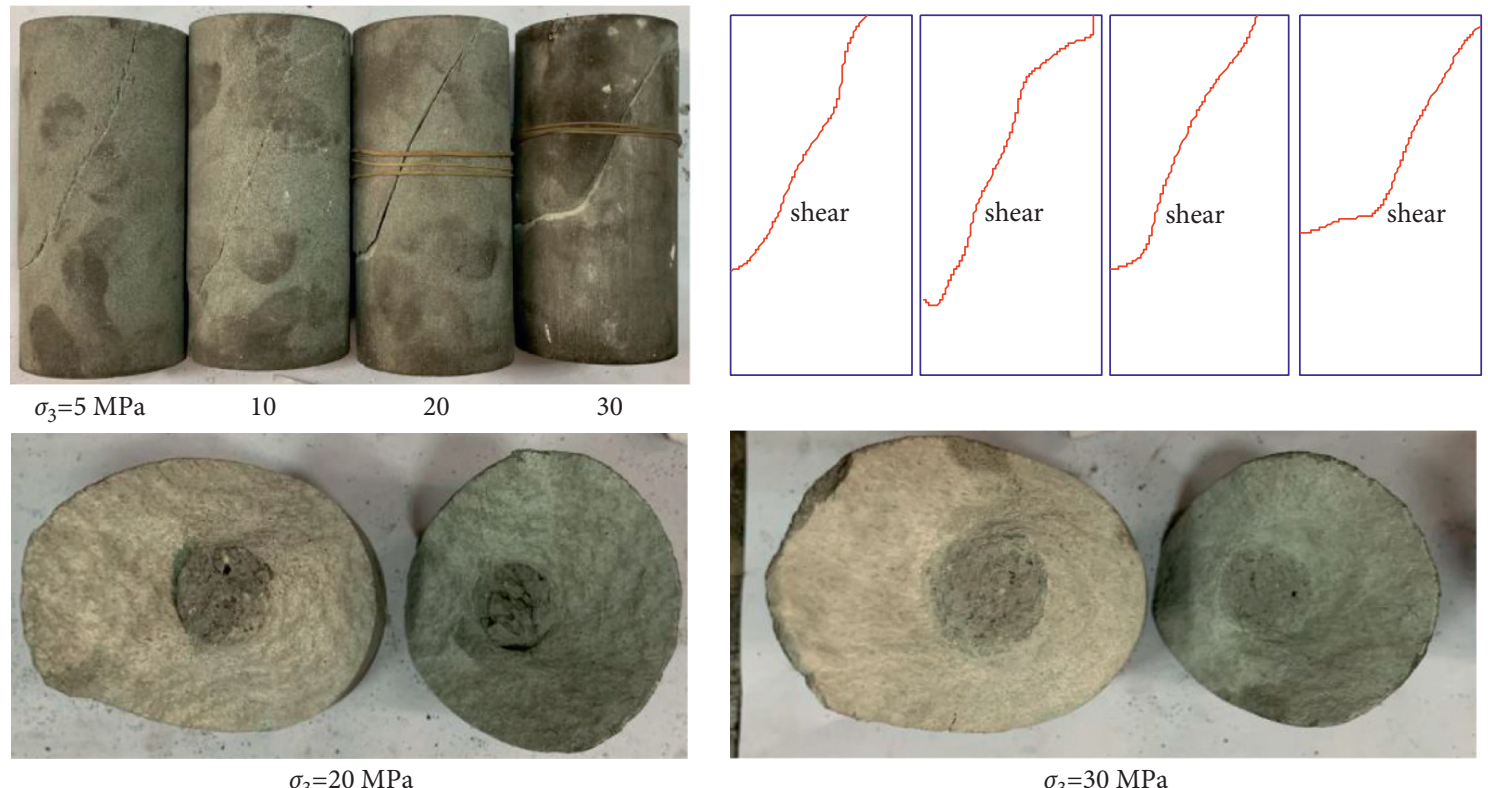

(d)

FIGURE 9: Failure modes of specimens under triaxial compression: (a) SC specimens, (b) HC specimens, (c) HC-LSCM specimens, and (d) HC-HSCM specimens.

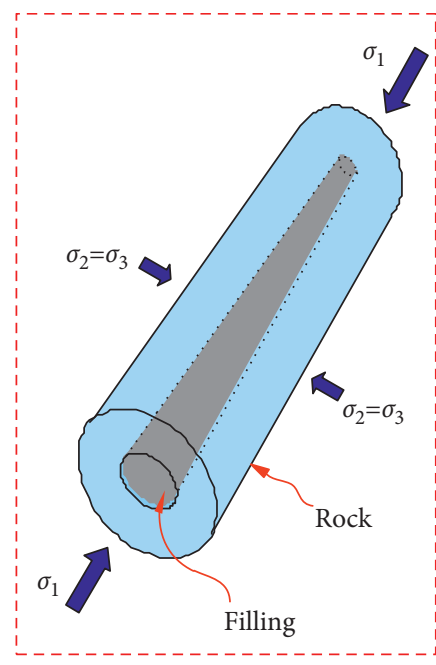

(a)

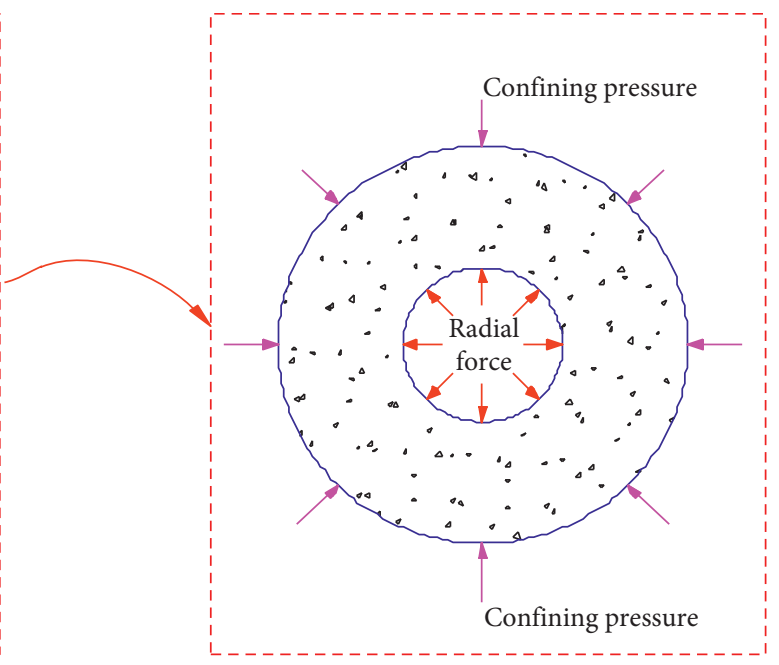

(b)

FIGURE 10: Relations between the surrounding rock and the support: (a) physical modelling in the laboratory and (b) stress state of the surrounding rock in plane view.

\section{Conclusion}

This study conducts unconfined and triaxial compression tests on hollowed specimens with different inclusions in an attempt to investigate the interactions between the surrounding rock and the support. To do this, the solid cylindrical specimens, hollowed cylindrical specimens, and hollowed cylindrical specimens with two cement mortars were prepared and then tested. The effects of the infilling on the stress-strain behaviors, deformation features, mechanical characteristics, and the failure patterns were deeply investigated. The following main conclusions can be drawn:

(1) Upon the unconfined compression condition, all the specimens exhibit a remarkable stress drop at the onset of failure, indicating a typical brittle failure mode. However, under the triaxial compression condition, each infilled specimen exhibits residual carrying capacity though a slight stress drop occurs after the peak stress. 
(2) Both the elastic and plastic strains increase with ascending the confining pressure for all the test scenarios. The crack closure strains show monotonic increase trends for all the four test scenarios when the confining pressure changes from $5 \mathrm{MPa}$ to $30 \mathrm{MPa}$. The crack closure strain derived from the unconfined compression test is greater than those obtained from the triaxial compression with relative low confining pressures.

(3) A greater confining pressure leads to much higher elastic modulus and strength. Considering the infilling effect, the elastic modulus has no conclusive change trend under the same confining pressure, whereas the infilling has significant impacts on the strength enhancement of the specimens. The solid specimens exhibit the highest strengths compared to the other three groups of specimens. The cement mortar exerts a positive effect on the carrying capacity of the rock, and the infilling having a higher strength and stiffness contributes to a more pronounced enhancement of the strength.

(4) Under the unconfined compression condition, the four groups of the specimens fail mainly in shear manners with a few local tensile fractures. Under the triaxial compression condition, however, merely a dominated shear fracture can be seen on the surfaces. For the infilled specimens under low confining pressures $\left(\sigma_{3}=5 \mathrm{MPa}\right.$ and $\left.10 \mathrm{MPa}\right)$, rock fragments are still tightly stuck with the cement mortar apart from the main shear fracture. However, under high confining pressure $\left(\sigma_{3}=20 \mathrm{MPa}\right.$ and $\left.30 \mathrm{MPa}\right)$, both the rock and the cement mortar were cut into two parts by the shear fracture.

\section{Data Availability}

The data used to support the findings of this study are available from the corresponding author upon request.

\section{Conflicts of Interest}

The authors declare that they have no conflicts of interest.

\section{Acknowledgments}

This work was supported by the Natural Science Foundation of Hunan Province (grant nos. 2019JJ50152 and 2020JJ5188) and the Scientific Research Fund of Hunan Provincial Education Department (grant no. 18B210).

\section{References}

[1] J. B. Martino and N. A. Chandler, "Excavation-induced damage studies at the underground research laboratory," International Journal of Rock Mechanics and Mining Sciences, vol. 41, no. 8, pp. 1413-1426, 2004.

[2] Q. Wu, X. Li, L. Weng, Q. Li, Y. Zhu, and R. Luo, "Experimental investigation of the dynamic response of prestressed rockbolt by using an SHPB-based rockbolt test system,"
Tunnelling and Underground Space Technology, vol. 93, Article ID 103088, 2019.

[3] Z. Zhou, X. Cai, X. Li, W. Cao, and X. Du, "Dynamic response and energy evolution of sandstone under coupled static-dynamic compression: insights from experimental study into deep rock engineering applications," Rock Mechanics and Rock Engineering, vol. 53, no. 3, pp. 1305-1331, 2020.

[4] L. Weng, L. Huang, A. Taheri, and X. Li, "Rockburst characteristics and numerical simulation based on a strain energy density index: a case study of a roadway in linglong gold mine, China," Tunnelling and Underground Space Technology, vol. 69, pp. 223-232, 2017.

[5] T. Zhou, J. Zhu, and H. Xie, "Mechanical and volumetric fracturing behaviour of three-dimensional printing rock-like samples under dynamic loading," Rock Mechanics and Rock Engineering, vol. 53, no. 6, pp. 2855-2864, 2020.

[6] M. Tao, H. T. Zhao, Z. W. Li, and J. B. Zhu, "Analytical and numerical study of a circular cavity subjected to plane and cylindrical P-wave scattering," Tunnelling and Underground Space Technology, vol. 95, Article ID 103143, 2020.

[7] K. Du, R. Su, M. Tao, C. Yang, A. Momeni, and S. Wang, "Specimen shape and cross-section effects on the mechanical properties of rocks under uniaxial compressive stress," Bulletin of Engineering Geology and the Environment, vol. 78, no. 8, pp. 6061-6074, 2019.

[8] K. Peng, Z. Liu, Q. Zou, Q. Wu, and J. Zhou, "Mechanical property of granite from different buried depths under uniaxial compression and dynamic impact: an energy-based investigation," Powder Technology, vol. 362, pp. 729-744, 2020.

[9] Z. Chu, Z. Wu, Q. Liu, and B. Liu, “Analytical solution for lined circular tunnels in deep viscoelastic Burgers rock considering the longitudinal discontinuous excavation and sequential installation of liners," Journal of Engineering Mechanics, vol. 147, no. 4, pp. 1-22, 2021.

[10] L. Weng, X. Li, A. Taheri, Q. Wu, and X. Xie, "Fracture evolution around a cavity in brittle rock under uniaxial compression and coupled static-dynamic loads," Rock Mechanics and Rock Engineering, vol. 51, no. 2, pp. 531-545, 2018.

[11] Q. Wu, L. Weng, Y. Zhao, B. Guo, and T. Luo, "On the tensile mechanical characteristics of fine-grained granite after heating/cooling treatments with different cooling rates," Engineering Geology, vol. 253, pp. 94-110, 2019.

[12] X. Guo, Z. Zhao, X. Gao, X. Wu, and N. Ma, "Analytical solutions for characteristic radii of circular roadway surrounding rock plastic zone and their application," International Journal of Mining Science and Technology, vol. 29, no. 2, pp. 263-272, 2019.

[13] K. Wu, Z. Shao, and S. Qin, "An analytical design method for ductile support structures in squeezing tunnels," Archives of Civil and Mechanical Engineering, vol. 20, no. 3, p. 91, 2020.

[14] X. Cai, Z. Zhou, and X. Du, "Water-induced variations in dynamic behavior and failure characteristics of sandstone subjected to simulated geo-stress," International Journal of Rock Mechanics and Mining Sciences, vol. 130, Article ID 104339, 2020.

[15] K. Mogi, "Fracture and flow of rocks under high triaxial compression," Journal of Geophysical Research, vol. 76, no. 5, pp. 1255-1269, 1971.

[16] C. Su, J. Qiu, Q. Wu, and L. Weng, "Effects of high temperature on the microstructure and mechanical behavior of hard coal," International Journal of Mining Science and Technology, vol. 30, no. 5, pp. 643-650, 2020. 
[17] S. You, H. Ji, V. Labiouse, S. A. Hall, and G. Viggiani, "Quantitative analysis of deformation in hollow cylinder tests on anisotropic clay formations," International Journal of Mining Science and Technology, vol. 25, no. 2, pp. 299-303, 2015.

[18] F. J. Santarelli and E. T. Brown, "Failure of three sedimentary rocks in triaxial and hollow cylinder compression tests," International Journal of Rock Mechanics and Mining Science \& Geomechanics Abstracts, vol. 26, no. 5, pp. 401-413, 1989.

[19] N. C. Gay, "Fracture growth around openings in thick-walled cylinders of rock subjected to hydrostatic compression," International Journal of Rock Mechanics and Mining Science \& Geomechanics Abstracts, vol. 10, pp. 231-43, 1973.

[20] M. I. Alsayed, "Utilising the hoek triaxial cell for multiaxial testing of hollow rock cylinders," International Journal of Rock Mechanics and Mining Sciences, vol. 39, no. 3, pp. 355-366, 2002.

[21] V. Labiouse and T. Vietor, "Laboratory and in situ simulation tests of the excavation damaged zone around galleries in opalinus clay," Rock Mechanics and Rock Engineering, vol. 47, no. 1, pp. 57-70, 2014.

[22] D.-H. Lee, C. H. Juang, H.-M. Lin, and S.-H. Yeh, "Mechanical behavior of Tien-liao mudstone in hollow cylinder tests," Canadian Geotechnical Journal, vol. 39, no. 3, pp. 744-756, 2002.

[23] A. S. Elkadi and J. G. M. Mier, "Experimental investigation of size effect in concrete fracture under multiaxial compression," International Journal of Fracture, vol. 140, no. 1-4, pp. 55-71, 2006.

[24] R. T. Ewy and N. G. W. Cook, "Deformation and fracture around cylindrical openings in rock-I. Observations and analysis of deformations," International Journal of Rock Mechanics and Mining Science of Geomechanics Abstracts, vol. 27, no. 5, pp. 387-407, 1990.

[25] R. T. Ewy and N. G. W. Cook, "Deformation and fracture around cylindrical openings in rock-II. initiation, growth and interaction of fractures," International Journal of Rock Mechanics and Mining Science \& Geomechanics Abstracts, vol. 27, no. 5, pp. 409-427, 1990.

[26] V. Labiouse, C. Sauthier, and S. You, "Hollow cylinder simulation experiments of galleries in boom clay formation," Rock Mechanics and Rock Engineering, vol. 47, no. 1, pp. 43-55, 2014.

[27] X. Chen, C. P. Tan, and C. M. Haberfield, "Numerical evaluation of the deformation behaviour of thick-walled hollow cylinders of shale," International Journal of Rock Mechanics and Mining Sciences, vol. 37, no. 6, pp. 947-961, 2000.

[28] T. Meier, E. Rybacki, A. Reinicke, and G. Dresen, "Influence of borehole diameter on the formation of borehole breakouts in black shale," International Journal of Rock Mechanics and Mining Sciences, vol. 62, pp. 74-85, 2013.

[29] S.-Q. Yang, "Experimental study on deformation, peak strength and crack damage behavior of hollow sandstone under conventional triaxial compression," Engineering Geology, vol. 213, pp. 11-24, 2016.

[30] S.-Q. Yang, "Fracturing mechanism of compressed hollowcylinder sandstone evaluated by X-ray micro-CT scanning," Rock Mechanics and Rock Engineering, vol. 51, no. 7, pp. 2033-2053, 2018.

[31] S. Wang, X. Li, K. Du, S. Wang, and M. Tao, "Experimental study of the triaxial strength properties of hollow cylindrical granite specimens under coupled external and internal confining stresses," Rock Mechanics and Rock Engineering, vol. 51, no. 3, pp. 1-17, 2018.
[32] H. Zhou, Y. Jiang, J. Lu, Y. Gao, and J. Chen, "Development of a hollow cylinder torsional apparatus for rock," Rock $\mathrm{Me}$ chanics and Rock Engineering, vol. 51, no. 12, pp. 3845-3852, 2018.

[33] Z. Li, H. Zhou, Y. Jiang, D. Hu, and C. Zhang, "Methodology for establishing comprehensive stress paths in rocks during hollow cylinder testing," Rock Mechanics and Rock Engineering, vol. 52, no. 4, pp. 1055-1074, 2019.

[34] C. Wang, "The optimal support intensity for coal mine roadway tunnels in soft rocks," International Journal of Rock Mechanics and Mining Sciences, vol. 37, no. 7, pp. 1155-1160, 2000.

[35] T. Zhou, J. B. Zhu, Y. Ju, and H. P. Xie, "Volumetric fracturing behavior of $3 \mathrm{~d}$ printed artificial rocks containing single and double 3d internal flaws under static uniaxial compression," Engineering Fracture Mechanics, vol. 205, pp. 190-204, 2019.

[36] Q. Wu, L. Chen, B. Shen, B. Dlamini, S. Li, and Y. Zhu, "Experimental investigation on rockbolt performance under the tension load," Rock Mechanics and Rock Engineering, vol. 52, no. 11, pp. 4605-4618, 2019.

[37] Y. Yokota, Z. Zhao, W. Nie, K. Date, K. Iwano, and Y. Okada, "Experimental and numerical study on the interface behaviour between the rock bolt and bond material," Rock Mechanics and Rock Engineering, vol. 52, no. 3, pp. 869-879, 2019.

[38] Q.-h. Wu, X.-b. Li, M. Tao, F.-j. Zhao, L. Weng, and L.-j. Dong, "Conventional triaxial compression on hollow cylinders of sandstone with various fillings: relationship of surrounding rock with support," Journal of Central South University, vol. 25, no. 8, pp. 1976-1986, 2018.

[39] S. A. Wade, J. M. Nixon, A. K. Schindler, and R. W. Barnes, "Effect of temperature on the setting behavior of concrete," Journal of Materials in Civil Engineering, vol. 22, no. 3, pp. 214-222, 2010.

[40] J. Peng, G. Rong, M. Cai, and C.-B. Zhou, "A model for characterizing crack closure effect of rocks," Engineering Geology, vol. 189, pp. 48-57, 2015.

[41] G. Rong, M. D. Yao, J. Peng, S. Sha, and J. Tan, "Influence of initial thermal cracking on physical and mechanical behaviour of a coarse marble: insights from uniaxial compression tests with acoustic emission monitoring," Geophysical Journal International, vol. 214, pp. 1886-1900, 2018.

[42] L. Weng, Z. Wu, and Q. Liu, "Dynamic mechanical properties of dry and water-saturated siltstones under sub-zero temperatures," Rock Mechanics and Rock Engineering, vol. 53, no. 10, pp. 4381-4401, 2020.

[43] M. S. Diederichs, P. K. Kaiser, and E. Eberhardt, "Damage initiation and propagation in hard rock during tunnelling and the influence of near-face stress rotation," International Journal of Rock Mechanics and Mining Sciences, vol. 41, no. 5, pp. 785-812, 2004.

[44] Q. Wu, L. Weng, Y. Zhao, F. Zhao, W. Peng, and S. Zhang, "Deformation and cracking characteristics of ring-shaped granite with inclusion under diametrical compression," Arabian Journal of Geosciences, vol. 13, no. 14, p. 681, 2020.

[45] L. V. Rabcewicz, The New Austrian Tunnelling Method, Springer Berlin Heidelberg, Berlin, Germany, 2008. 